\title{
Coping styles in relation to cognitive rehabilitation and quality of life after brain injury
}

Citation for published version (APA):

Wolters, G., Stapert, S. Z., Brands, I., \& van Heugten, C. M. (2010). Coping styles in relation to cognitive rehabilitation and quality of life after brain injury. Neuropsychological Rehabilitation, 20(4), 587-600. https://doi.org/10.1080/09602011003683836

Document status and date:

Published: 01/01/2010

DOI:

10.1080/09602011003683836

Document Version:

Publisher's PDF, also known as Version of record

Document license:

Taverne

Please check the document version of this publication:

- A submitted manuscript is the version of the article upon submission and before peer-review. There can be important differences between the submitted version and the official published version of record.

People interested in the research are advised to contact the author for the final version of the publication, or visit the DOI to the publisher's website.

- The final author version and the galley proof are versions of the publication after peer review.

- The final published version features the final layout of the paper including the volume, issue and page numbers.

Link to publication

\footnotetext{
General rights rights.

- You may freely distribute the URL identifying the publication in the public portal. please follow below link for the End User Agreement:

www.umlib.nl/taverne-license

Take down policy

If you believe that this document breaches copyright please contact us at:

repository@maastrichtuniversity.nl

providing details and we will investigate your claim.
}

Copyright and moral rights for the publications made accessible in the public portal are retained by the authors and/or other copyright owners and it is a condition of accessing publications that users recognise and abide by the legal requirements associated with these

- Users may download and print one copy of any publication from the public portal for the purpose of private study or research.

- You may not further distribute the material or use it for any profit-making activity or commercial gain

If the publication is distributed under the terms of Article $25 \mathrm{fa}$ of the Dutch Copyright Act, indicated by the "Taverne" license above, 


\section{Neuropsychological Rehabilitation}

\section{Coping styles in relation to cognitive rehabilitation and quality of life after brain injury}

\section{Gisela Wolters , Sven Stapert , Ingrid Brands \& Caroline Van Heugten}

To cite this article: Gisela Wolters, Sven Stapert , Ingrid Brands \& Caroline Van Heugten (2010) Coping styles in relation to cognitive rehabilitation and quality of life after brain injury, Neuropsychological Rehabilitation, 20:4, 587-600, DOI: 10.1080/09602011003683836

To link to this article: https://doi.org/10.1080/09602011003683836

\section{Published online: 05 May 2010.}

Submit your article to this journal $\sqsubset$

Џ Article views: 1118

Q View related articles $\longleftarrow$

Citing articles: 12 View citing articles 


\title{
Coping styles in relation to cognitive rehabilitation and quality of life after brain injury
}

\author{
Gisela Wolters ${ }^{1,3}$, Sven Stapert ${ }^{2}$, Ingrid Brands ${ }^{3}$, and \\ Caroline Van Heugten ${ }^{1,2}$
}

${ }^{1}$ Faculty of Health, Medicine and Life Sciences, School for Mental Health and Neuroscience, Maastricht University, Maastricht, The Netherlands; ${ }^{2}$ Faculty of Psychology, Department of Neuropsychology and Psychopharmacology, Maastricht University, Maastricht, The Netherlands; ${ }^{3}$ Neurology Department, Rehabilitation Centre Blixembosch, Eindhoven, The Netherlands

\begin{abstract}
This study investigated the changes in coping styles of patients with acquired brain injury who underwent cognitive rehabilitation, and the effects of these changes on their quality of life. Participants were 110 patients in the chronic phase post-injury, who underwent outpatient cognitive rehabilitation according to current guidelines and standards. Coping style (Utrecht Coping List) was measured at the start of rehabilitation (T0) and repeated at least 5 months later (T1). Coping style was related to quality of life measured at T1 (Life Satisfaction Questionnaire and Stroke-Adapted Sickness Impact Profile). Results indicated that active problem-focused coping styles decreased and passive emotion-focused coping styles increased significantly between T0 and T1. Furthermore, the study showed that increases in active problem-focused coping styles and decreases in passive emotion-focused coping styles predicted a higher quality of life in the long term. These changes in coping styles are adaptive for the adjustment process in the chronic phase post-injury. Overall however, most participants showed maladaptive changes in coping styles. Implications for cognitive rehabilitation are therefore discussed.
\end{abstract}

Keywords: Brain injuries; Coping; Quality of life; Psychological adjustment; Rehabilitation

Correspondence should be sent to Gisela Wolters, Maastricht University, School for Mental Health and Neuroscience, P.O. Box 616 (drt12), 6200 MD Maastricht, The Netherlands. E-mail: g.woltersgregorio@np.unimaas.nl

(C) 2010 Psychology Press, an imprint of the Taylor \& Francis Group, an Informa business http://www.psypress.com/neurorehab

DOI:10.1080/09602011003683836 


\section{INTRODUCTION}

Acquired brain injury is a significant health problem, with an annual incidence in The Netherlands alone varying between 1 and 1.7 per 1000 cases (Brouwer, van Zomeren, Berg, Bouma, \& de Haan, 2002). In the long term, a significant number of patients with brain injury experience problems in their daily life (Finset \& Andersson, 2000; Hoofien, Gilboa, Vakil, \& Donovick, 2001; McCarthy et al., 2006). Moreover, it has been reported repeatedly that many patients suffer from poor psychosocial adjustment and experience a reduced quality of life (Engberg \& Teasdale, 2004; Hoofien et al., 2001; Pagulayan, Temkin, Machamer, \& Dikmen, 2006; Tomberg, Toomela, Pulver, \& Tikk, 2005). These negative after-effects increase the difficulty of successful adaptation to the new reality.

Recent studies have indicated that the way patients cope with the negative effects of the trauma and with problems in everyday life has a major influence on the adaptation process (Anson \& Ponsford, 2006a; Chronister \& Chan, 2006; Finset \& Andersson, 2000). Coping refers to "the person's cognitive and behavioural efforts to manage (reduce, minimise, master, or tolerate) the internal and external demands of the person-environment transaction that is appraised as taxing or exceeding the person's resources" (Folkman, Lazarus, Gruen, \& DeLongis, 1986, p. 572). Coping styles can be problem-focused or emotion-focused (Lazarus \& Folkman, 1985). Problem-focused coping styles involve actively addressing and confronting the problem. The patient either tries to change the stressful situation or tries to gather more information or skills (Folkman et al., 1986). Emotion-focused coping styles involve regulating the emotional reaction that the problem elicits, and not in changing the stressful situation. These styles can include distraction, suppression of emotions, reassuring thoughts, and accepting situations more easily (Cook \& Heppner, 1997). More active methods to regulate the emotional reactions are avoidance, expression of emotions, and seeking social support (Lazarus, 1993).

Emotion-focused styles have been reported to increase and problemfocused styles to decrease during the first months after brain injury (Dawson, Catanzaro, Firestone, Schwartz, \& Stuss, 2006; Hepp, Moergeli, Buchi, Wittmann, \& Schnyder, 2005). Some researchers found that although coping styles did not influence quality of life in the acute or post-acute phase, i.e., between 0 and 6 months post-injury, they were important determinants of quality of life in the chronic phase, i.e., after 6 months post-injury. In this phase, patients have to deal with their, often permanent, disability (Darlington et al., 2007). Other researchers reported that utilising emotion-focused styles in the acute phase and problem-focused styles in the chronic phase is most beneficial for the adjustment process (Dawson et al., 2006; Hepp et al., 2005; Krpan, Levine, Stuss, \& Dawson, 2007). Hence, it has been assumed that cognitive rehabilitation should focus on training problem-focused 
coping styles in the chronic phase after brain injury (Krpan et al., 2007; Tomberg et al., 2005; Wilson, 2000).

The aim of outpatient cognitive rehabilitation is, on the one hand, to teach both the patient and the family to adapt their lifestyle, while taking into account the severity of cognitive and behavioural problems. On the other hand, patients need to be stimulated to learn skills and compensation strategies that promote the return to activities of daily life and participation in society (Wilson, 2000). This implies that training active problem-focused coping styles is already an important goal of cognitive rehabilitation. This also means that rehabilitation practitioners assume that coping styles are dynamic and therefore modifiable. Recently, Anson and Ponsford (2006b) investigated the effect of a five-week cognitive-behaviour therapy-based intervention, in which active problem-focused coping styles were explicitly trained. Patients with traumatic brain injury reported using more active problem-focused coping styles after the intervention. This study is promising because it showed that coping styles are amenable to rehabilitation. Learning to use these problem-focused coping styles is assumed to increase a patient's quality of life, but scientific evidence to support this hypothesis is lacking.

The objectives of the present study were therefore to investigate the changes in coping styles in a group of patients who underwent outpatient cognitive rehabilitation in the chronic phase after brain injury, and to examine the influence of changes in coping styles on their quality of life. We hypothesised that patients would come to rely more on problem-focused coping styles and less on emotion-focused coping styles over the course of and after rehabilitation. Furthermore, we expected to find that patients who learn to use more problem-focused coping styles and less emotion-focused coping styles in the chronic phase would experience a higher quality of life.

\section{METHODS}

\section{Participants}

Patients included in this study had been referred to an outpatient cognitive rehabilitation programme by neurologists, general practitioners, rehabilitation physicians or psychologists, between 2000 and 2008. Inclusion criteria for the programme were: acquired brain injury confirmed by neurological and/or neuroimaging data; a minimum age of 17 years; presence of cognitive, behavioural and/or emotional symptoms that interfered with the demands of daily life; and a sufficient command of the Dutch language. Patients with primary behavioural or psychiatric problems, severe aphasia, degenerative brain disease, whiplash or head injury (no loss of consciousness or post-traumatic amnesia), chronic substance abuse, or premorbid adjustment problems, such as personality 
disorders or social maladaptation, were excluded from the programme. These criteria were checked in the intake procedure.

Additional inclusion criteria for participation in the study were: completion of the Utrecht Coping List (UCL) at the start of rehabilitation as part of routine clinical care; a period of at least six months between the brain injury and the start of rehabilitation; and at least five months between the start of rehabilitation and the moment when the questionnaires were sent out. The period of five months was chosen because average treatment time is between 3 and 5 months, thereby ensuring that patients had received sufficient treatment. Therefore, most patients had either finished the programme or made low frequent follow-up visits to the rehabilitation practitioner or neuropsychologist, to monitor their adaptation process and check for new treatment goals.

\section{Procedure}

Baseline measurements were carried out at the start of rehabilitation (T0) and follow-up measurements were conducted at least five months after the start of rehabilitation (T1). The following data were collected from the files of patients who met all inclusion criteria: demographic data (gender, level of educational attainment, date of birth); lesion characteristics (type of lesion, side of lesion, date of brain injury, date of T0); and scores on the UCL (T0). The eligible patients were contacted by mail. The UCL, Stroke-Adapted Sickness Impact Profile (SA-SIP30), Life Satisfaction Questionnaire (LiSat-9), an information letter, and a consent form were sent to these patients. Patients who completed the questionnaires and consented were included in the study.

\section{Intervention}

The overall goal of the cognitive rehabilitation programme is to teach patients and their caregivers to live with, manage, compensate for, and adapt to the consequences of the brain injury in order to maximise social participation. The programme is based on principles of neuropsychological rehabilitation as described by Prigatano (1999), and has a modular character. Different combinations of modules are offered, depending on the individual needs and goals of the patient and/or the family. Both individual and/or group sessions are provided. Individual sessions consist of education, learning specific compensation strategies, problem-solving skills, and self-management techniques. Group sessions are provided as open groups to provide emotional support and address the emotional adjustment process. Neuropsychologists together with cognitive and occupational therapists administer the cognitive rehabilitation programme. Speech therapists are involved when specific communication problems need to be addressed. The cognitive rehabilitation programme was developed as an integrated multi-disciplinary treatment programme. The duration of the rehabilitation programme is different for each 
individual and determined by the time that patients require to meet their own goals, with the aim to improve adaptation and compensation. In the beginning, the intensity of cognitive rehabilitation is on average $1-3$ hours per week and this gradually decreases over time. The average duration of the programme is $3-5$ months.

\section{Measurements}

The UCL is a self-reporting questionnaire used to measure coping styles. Each of the 47 items is answered on a 4-point scale $(1=$ seldom/never, $2=$ occasionally, $3=$ frequently, $4=$ very often). The UCL consists of seven different subscales that assess problem-focused coping (active problem solving), and emotion-focused coping (palliative reactions, avoidance, seeking social support, passive reactions, expression of emotions, and reassuring thoughts). The present study focused on the active problem-solving coping scale and the passive reactions coping scale, since these differentiate both focus (emotion vs. problem) and approach (active vs. passive). The problem-solving scale represents active coping (e.g., tackling a problem at once, seeing problems as a challenge and remaining calm in difficult situations). The passive reactions scale represents passive coping (e.g., isolating oneself from others, worrying about the past and taking refuge in fantasies) (Schreurs, van de Willege, Brosschot, Tellegen, \& Graus, 1993; Van Baalen et al., 2007). The active problem-solving coping scale and the passive coping scale show fairly good internal consistency (Cronbach's alpha .78 and .74, respectively) in the general Dutch population. The re-test reliability of both scales is reasonably high, with a Cronbach's alpha of .62 for the active problem-solving scale and .74 for the passive scale (Schreurs et al., 1993). Change scores are calculated by subtracting coping scores at $\mathrm{T} 0$ from coping scores at $\mathrm{T} 1$.

The SA-SIP30 is a disease-specific questionnaire that measures the quality of life of a patient and it is the adapted version of the Sickness Impact Profile (SIP). The SA-SIP30 uses 30 items of the original 136 items. The internal consistency is high (Cronbach's alpha .85) and the validity is good and similar to the original version (vanStraten et al., 1997). Scores are converted to a $0-100$ scale, with lower scores indicating better disease-specific quality of life. SA-SIP30 score of 33 or higher indicates many limitations in daily life (vanStraten et al., 1997).

The LiSat-9 is a generic instrument for measuring quality of life. The questionnaire consists of 9 items and these are valued on a 6-point scale from 1 (very unsatisfactory) to 6 (very satisfactory). One public domain is measured, viz., satisfaction with life, and eight specific fields are covered (Fugl-Meyer, Branholm, \& Fugl-Meyer, 1991). Total score range is between 9 and 54. An average score of generic quality of life (LiSat-9 score) is computed by adding all scores on the 9 items and dividing them by nine (Post, de Witte, van 
Asbeck, van Dijk, \& Schrijvers, 1998). Mean score of 1-4 constitutes dissatisfaction with life and a score of 5 or 6 indicates satisfaction. The Dutch translation of the LiSat-9 has been used before with stroke patients and it has been shown that its reliability is satisfactory to good (Cronbach's alpha .74.82) (Post et al., 1998; Visser-Meily, Post, Schepers, \& Lindeman, 2005).

The Medical Ethics Committee of Maastricht University Medical Centre and the Research Committee of the Rehabilitation Centre Blixembosch approved this study. Written informed consent was obtained from all participants.

\section{Data analyses}

Participants were grouped by level of education according to a formal schooling system often used in The Netherlands (De Bie, 1987), viz., those with primary education (LE low), those with junior vocational training (LE average), and those with senior vocational training (LE high); these correspond to $8.6 \pm 1.9$, $11.4 \pm 2.5,15.2 \pm 3.3$ years of full-time education, respectively.

Four one-sample $t$-tests were carried out to investigate the score differences on the problem-solving coping scale and the passive coping scale between the men and women in the study, and the men and women of the standardisation sample (Schreurs et al., 1993). Two paired $t$-tests were carried out to investigate the changes in the problem-solving scale and the passive coping scale between T0 and T1. Furthermore, we established which changes in coping styles were predictive for quality of life. We conducted two linear regression analyses with LiSat-9 score and SA-SIP30 score as the dependent variables. The following predictors were included in these models: age, gender, level of educational attainment, time between injury and $\mathrm{T} 0$, time between $\mathrm{T} 0$ and $\mathrm{T} 1$, scores on the active problemsolving scale and the passive scale at $\mathrm{T} 0$, change scores on the problemsolving scale and the passive scale. Gender was dummy coded with woman $=1$ and $\operatorname{man}=0$. Level of education was dummy coded with two dummies (LE low and LE high), with LE average as the reference category. The assumptions of regression analysis were tested for each model. All statistical analyses were conducted using the SPSS 16.0 for Windows software package.

\section{RESULTS}

\section{Participant characteristics}

Questionnaires were sent to 141 patients who met the inclusion criteria. The final sample consisted of 110 participants (i.e., response rate 78\%). Reasons to decline participation were: work or study-related factors that prohibited participation, avoidance and/or anxiety, or health-related problems unrelated 
TABLE 1

Demographics and injury-related variables

\begin{tabular}{llcc}
\hline & & Mean $($ SD) & Range \\
\hline Age (years) & At injury & $42.3(14.0)$ & $0.5-68.7$ \\
Time (years) & At T0 & $45.1(12.8)$ & $17.0-70.2$ \\
& Between injury and T0 & $2.8(4.6)$ & $0.5-32.1$ \\
& Between T0 and T1 & $1.5(0.9)$ & $0.4-5.5$ \\
\hline \multirow{3}{*}{ Lex } & & Frequency & $\%$ \\
\hline \multirow{3}{*}{ Type of lesion } & Man & 62 & 56.4 \\
& Low & 28 & 25.5 \\
& Average & 42 & 38.2 \\
& High & 40 & 36.4 \\
Side of lesion & CVA & 48 & 43.6 \\
& TBI & 30 & 27.3 \\
& Other & 13 & 11.8 \\
& Multiple & 19 & 17.3 \\
& Left & 29 & 26.4 \\
& Right & 35 & 31.8 \\
& Bilateral & 7 & 6.4 \\
& Unspecified & 39 & 35.5 \\
\hline
\end{tabular}

$\mathrm{T} 0=$ completion of questionnaire at the start of rehabilitation; $\mathrm{T} 1=$ completion of questionnaires for the second time; CVA = cerebrovascular accident; $\mathrm{TBI}=$ traumatic brain injury; Other $=$ tumour ( $n=7)$, hydrocephalus $(n=2)$, anoxia $(n=1)$, meningitis $(n=1)$, epilepsy $(n=1)$, axonal neuropathy $(n=1)$; Multiple $=$ more than one diagnosis: stroke and TBI $(n=12)$, stroke and meningitis $(n=1)$, stroke and epilepsy $(n=2)$, encephalitis and epilepsy $(n=1)$, TBI and epilepsy $(n=$ $1)$, stroke and TBI and epilepsy $(n=1)$, stroke and TBI and meningitis and epilepsy $(n=1)$.

to brain injury. Table 1 provides demographic and injury-related information. The mean age at the time of injury was 42 years $(S D=14)$. Overall more men than women participated (56\%). Most participants had suffered a stroke $(59 \%)$, of whom $15 \%$ had a multiple diagnosis.

\section{Coping styles and quality of life}

Table 2 presents an overview of the coping styles used by our sample at T0 and T1. In general, at T0 participants were more likely to use passive coping and less likely to use problem-solving coping, compared to the standardisation sample (Schreurs et al., 1993). The difference on the passive scale between the men and women in the current study and the men and women in the standardisation sample was significant, viz., $t(61)=$ $3.57, p=.001$ and $t(47)=3.75, p<.001$, respectively. Also the difference on the problem-solving scale between the women in the current study and 
TABLE 2

Coping styles of the patients using the $\mathrm{UCL}$

\begin{tabular}{|c|c|c|c|c|c|c|c|c|}
\hline \multirow[b]{2}{*}{ UCL scales } & \multicolumn{3}{|c|}{ TO } & \multicolumn{3}{|c|}{$T 1$} & \multirow{2}{*}{$\begin{array}{c}\text { Mean (SD) } \\
\text { Standardisation } \\
\text { group: men }\end{array}$} & \multirow{2}{*}{$\begin{array}{c}\text { Mean }(S D) \\
\text { Standardisation } \\
\text { group: women }\end{array}$} \\
\hline & Mean $(S D)$ men & Mean $(S D)$ women & Range & Mean $(S D)$ men & Mean $(S D)$ women & Range & & \\
\hline Problem-solving $(7-28)^{*}$ & $18.2(4.0)$ & $17.5(3.5)$ & $9-28$ & $16.9(4.4)$ & $16.7(3.8)$ & $7-27$ & $18.3(3.5)$ & $19.3(5.1)$ \\
\hline Passive $(7-28)^{*}$ & $12.2(3.3)$ & $12.6(3.1)$ & $7-24$ & $13.4(4.2)$ & $12.7(3.6)$ & $7-23$ & $10.7(2.9)$ & $10.9(5.4)$ \\
\hline
\end{tabular}

* Possible range of scores. The standardisation group of men consists of men $(n=1493)$ between the ages of 19 and 65 . The standardisation group of women consists of women $(n=712)$ between the ages of 18 and 65 ; T0 = baseline measurements; T1 = follow-up measurements. 
the women in the standardisation sample was significant, viz., $t(47)=-3.61$, $p=.001$. However, no significant differences were evident between the men in the current study and the men in the standardisation sample on the problemsolving scale, $t(61)=-0.31, p=.761$.

On the LiSat-9, participants indicated that they were dissatisfied with life ( $M$ $=4.2, S D=0.8)$. The score of the SA-SIP30 approached the cut-off score of $33(M=28.1, S D=16.9)$. On the SA-SIP30, patients showed the greatest dysfunction when it came to alertness $(M=67.0 ; S D=35.7)$. Examples of this scale include "I make more mistakes than usual" and "I have difficulty doing activities involving concentration and thinking". The least dysfunction was reported in the case of bodily care and taking exercise $(M=9.1, S D=17.1)$.

\section{Changes in coping styles}

Significant changes in the problem-solving coping scale and the passive coping scale results were revealed between T0 and T1. Patients used less problemsolving coping at $\mathrm{T} 1(M=16.8, S D=4.1)$ than at $\mathrm{T} 0(M=17.9, S D=3.8)$, $t(109)=2.87, p<.01$. In contrast, more passive coping was used at T1 $(M$ $=13.1, S D=4.0)$ than at $\mathrm{T} 0(M=12.4, S D=3.2), t(109)=-2.20, p<.05$.

\section{Influence of changes in coping styles on the quality of life}

The regression model in Table 3 shows that changes in passive coping between $\mathrm{T} 0$ and $\mathrm{T} 1$ contributed significantly to the quality of life as measured by the SA-SIP30. Positive changes in passive coping predicted a higher SASIP30 score and thus a lower quality of life. The model could explain $42 \%$ of the variance in SA-SIP30 scores.

Increased use of problem-solving coping as well as decreased use of passive coping significantly predicted a higher quality of life as measured by the LiSat-9. Forty percent of the variance in LiSat-9 score could be attributed to the predictors in the model. In addition, passive coping at T0 accounted for a significant proportion of the variance in quality of life as measured by the SA-SIP30 and LiSat- $9\left(R^{2}=.12\right.$ and $R^{2}=.13$, respectively). The higher the score was on the passive scale at T0, the higher the score on the SA-SIP30, and the lower the score on the LiSat-9. Finally, time between $\mathrm{T} 0$ and $\mathrm{T} 1$ was a significant predictor for quality of life, that is, more time between the start of rehabilitation and the follow-up measurement predicted a higher quality of life in the long term.

\section{DISCUSSION}

The goals of this prospective longitudinal study were to examine the changes in coping styles of patients with brain injury who underwent outpatient cognitive 
TABLE 3

Multiple linear regression models for the quality of life measures

\begin{tabular}{|c|c|c|c|c|c|}
\hline Outcome variables & Predictors & $B$ & $S E B$ & $\beta$ & $t$ \\
\hline \multirow[t]{11}{*}{ SA-SIP30 level of dysfunction } & (Constant) & -9.63 & 12.76 & & -0.76 \\
\hline & Age at T0 & 0.19 & 0.11 & 0.14 & 1.68 \\
\hline & Gender & -0.48 & 2.66 & -0.01 & -0.18 \\
\hline & LE low & 4.32 & 3.55 & 0.11 & 1.22 \\
\hline & LE high & 0.10 & 3.21 & 0.00 & 0.03 \\
\hline & Time between injury and T0 & -0.14 & 0.31 & -0.04 & -0.45 \\
\hline & Time between $\mathrm{T} 0$ and $\mathrm{T} 1$ & -1.12 & 1.45 & -0.06 & -0.77 \\
\hline & $\mathrm{C}$ problem-solving & 0.00 & 0.40 & 0.00 & 0.01 \\
\hline & C passive & 2.43 & 0.45 & 0.49 & 5.39* \\
\hline & T0 problem-solving & -0.16 & 0.43 & -0.04 & -0.37 \\
\hline & T0 passive & 2.55 & 0.47 & 0.49 & $5.45^{*}$ \\
\hline \multirow[t]{11}{*}{ LiSat-9 quality of life } & (Constant) & 5.19 & 0.62 & & $8.39^{*}$ \\
\hline & Age at $\mathrm{T} 0$ & -0.01 & 0.01 & -0.08 & -0.89 \\
\hline & Gender & 0.21 & 0.13 & 0.13 & 1.66 \\
\hline & LE low & -0.01 & 0.17 & -0.01 & -0.08 \\
\hline & LE high & -0.26 & 0.16 & -0.16 & -1.64 \\
\hline & Time between injury and $\mathrm{T} 0$ & 0.02 & 0.02 & 0.10 & 1.19 \\
\hline & Time between $\mathrm{T} 0$ and $\mathrm{T} 1$ & 0.14 & 0.07 & 0.17 & $2.05^{*}$ \\
\hline & $\mathrm{C}$ problem-solving & 0.06 & 0.02 & 0.29 & 3.02* \\
\hline & $\mathrm{C}$ passive & -0.06 & 0.02 & -0.27 & $-2.91 *$ \\
\hline & T0 problem-solving & 0.02 & 0.02 & 0.11 & 1.12 \\
\hline & T0 passive & -0.11 & 0.02 & -0.45 & $-4.91^{*}$ \\
\hline
\end{tabular}

$R^{2}$ SA-SIP30 $=.42, R^{2}$ LiSat $9=.40(n=110) . B=$ unstandardised regression coefficient; $S E B$ $=$ standard error of the regression coefficients; $\beta=$ standardised regression coefficients. Age in years; Time in years; $\mathrm{T} 0=$ baseline measurements; $\mathrm{T} 1=$ follow up measurements; $\mathrm{C}=$ change score. Coding of the predictors: Gender: $\operatorname{man}=0$, woman $=1$; LE low: low educational attainment $=1$, average or high educational attainment $=0 ; \mathrm{LE}$ high: high educational attainment $=1$, low or average educational attainment $=0 .{ }^{*} \alpha<.05$.

rehabilitation in the chronic phase post-injury, and to examine the effect of changes in coping styles on quality of life. Contrary to our hypothesis, this study showed that, on average, levels of active problem-focused coping styles decreased and passive emotion-focused coping styles increased over the course of and after rehabilitation. Moreover, it also became clear that increases in active problem-focused coping styles and decreases in passive emotion-focused coping styles, predicted a high quality of life.

An explanation as to why active problem-focused coping styles decreased and passive emotion-focused coping styles increased is given by Kendall and Terry (1996). They suggest that patients become more realistic over the course of rehabilitation, because it becomes apparent that the problems to be faced are long-term and there are no ready solutions to these problems. Patients realise that their premorbid level of functioning will never be regained, and they 
have to deal with and accept their decreased capabilities. These increases in awareness may have underpinned the observed changes in coping style (Kendall \& Terry, 1996; Ownsworth \& McFarland, 2004).

Ben-Yishay (2008) and Goldstein (1952) offered another possible explanation for the average decrease of active problem-focused coping styles over the course of rehabilitation, which has also been observed in other studies. They postulated that in order to restore the patient's cognitive and functional life competencies to pre-injury levels, others must structure and modify the patient's environment so that the patient will be able to cope with the demands of confronting situations. Under those conditions, the patient will feel "in a state of health" and display or report active problemfocused coping styles. While this feeling is fostered during rehabilitation programmes it could be lost or altered when rehabilitation comes to an end.

In addition, it was shown that the use of passive coping styles in the chronic phase was predictive of less desirable quality of life outcomes in the long term. Moreover, passive styles were shown to be more prevalent in the patients in the current study compared to the general population. These findings are in line with previous studies that have shown that passive coping styles are most prevalent in the chronic phase following brain injury and that these styles are predictive for problems in everyday life (Dawson et al., 2006; Hepp et al., 2005; Krpan et al., 2007). Another finding of note was that patients with a longer period between the start of rehabilitation and the follow-up measurement reported a higher quality of life. It could be suggested that these patients have had more time to compensate for and adapt to the changes and consequently have a higher quality of life.

Some limitations of this study have to be acknowledged. First of all, injury characteristics such as injury type, location or severity, were not included in the regression models. The reason for this was that examining the influence of these characteristics on quality of life was not the main purpose of the present study. Furthermore, studies have generally found no effect of these variables on coping, so from a theoretical viewpoint we did not have to include these variables in the models (Anson \& Ponsford, 2006a; Finset \& Andersson, 2000; Herrmann et al., 2000). Moreover, although injury severity, as classified by Glasgow Coma Scale (GCS) scores or duration of post-traumatic amnesia (PTA), is likely to influence quality of life, studies have found no relations between severity and outcomes, such as emotional adjustment (Anson \& Ponsford, 2006a; Curran, Ponsford, \& Crowe, 2000). Dikmen (1995) has argued that injury severity is a better predictor of more objective indices, such as employment status, than of self-perceived psychosocial limitations. A second limitation is that the quality of life was not measured at the start of rehabilitation. Since there was no baseline measurement, no conclusions can be drawn regarding changes in quality of life over the course of rehabilitation. However, the present study did not aim to evaluate the effectiveness of the 
cognitive rehabilitation programme. Moreover, we assume that the quality of life at the start of rehabilitation is low, because this is the main reason for patients to enter a rehabilitation programme. Thirdly, we acknowledge that other factors, such as the presence of mood impairments, could have influenced the use of coping styles and quality of life. Curran et al. (2000) have shown that the use of emotion-focused coping styles was related to both depression and anxiety.

This study has a number of strengths. First of all, to the best of our knowledge, it is the first study to explore changes in coping styles over the course of an outpatient cognitive rehabilitation programme following acquired brain injury, with a prospective and longitudinal design. Secondly, the response rate was high $(78 \%)$. Thirdly, we decided not to apply strict inclusion and exclusion criteria, so the population would represent the broad spectrum of the heterogeneous cognitive rehabilitation population that one would encounter in regular clinical practice. Fourthly, the rehabilitation programme the patients underwent is a good reflection of current rehabilitation practices (Prigatano, 1999). Finally, quality of life is one of the most important outcome measures that cognitive rehabilitation is aiming to improve. By using both a disease-specific and a generic quality of life measure, we aimed to do justice to the complex construct referred to as quality of life.

Previous studies have already investigated the effects of contextual factors and injury characteristics on coping. High educational attainment predicted higher use of active problem-focused coping styles and a longer time period since injury predicted higher use of passive emotion-focused styles (Wolters, Stapert, Brands, \& van Heugten, in press). Research has also indicated that the effects of coping on quality of life become stronger in the chronic phase post-injury, while the effects of general functioning become less important (Darlington et al., 2007). The current longitudinal study is innovative because it shows that changes in coping styles account for a significant amount of unique variance in quality of life. However, although quality of life could be explained by almost half the variance in the models, other factors such as motivation, awareness, personality, learning styles, social support or family coping styles could also impede or enhance a patient's functioning and disability. Identifying other mechanisms that affect patients' quality of life would enable us to identify patients who may be in need of more intensive or more supportive ways of rehabilitation. In addition, variables amenable to cognitive rehabilitation, such as coping styles (Anson \& Ponsford, 2006b), can then provide opportunities to offer rehabilitation that is better tailored to a patient's needs and thus improve psychosocial adaptation.

For most persons with acquired brain injury, improving their quality of life is of major importance. This study has provided insight into the changes in coping styles in a patient population undergoing outpatient cognitive rehabilitation. These data emphasise the need for outpatient rehabilitation programmes to 
stimulate adaptive problem-focused coping styles explicitly in order to accomplish the highest possible quality of life for individual patients.

\section{REFERENCES}

Anson, K., \& Ponsford, J. (2006a). Coping and emotional adjustment following traumatic brain injury. Journal of Head Trauma Rehabilitation, 21, 248-259.

Anson, K., \& Ponsford, J. (2006b). Evaluation of a coping skills group following traumatic brain injury. Brain Injury, 20, 167-178.

Ben-Yishay, Y. (2008). Foreword. Neuropsychological Rehabilitation, 18, 513-521.

Brouwer, W., van Zomeren, A. H., Berg, I., Bouma, A., \& de Haan, E. (2002). Cognitive Rehabilitation: A Clinical Neuropsychological Approach. Amsterdam: Boom.

Chronister, J., \& Chan, F. (2006). A stress process model of caregiving for individuals with traumatic brain injury. Rehabilitation Psychology, 51, 190-201.

Cook, S. W., \& Heppner, P. P. (1997). A psychometric study of three coping measures. Educational and Psychological Measurement, 57, 906-923.

Curran, C. A., Ponsford, J. L., \& Crowe, S. (2000). Coping strategies and emotional outcome following traumatic brain injury: A comparison with orthopedic patients. Journal of Head Trauma Rehabilitation, 15, 1256-1274.

Darlington, A. S., Dippel, D. W., Ribbers, G. M., van Balen, R., Passchier, J., \& Busschbach, J. J. (2007). Coping strategies as determinants of quality of life in stroke patients: A longitudinal study. Cerebrovascular Diseases, 23, 401-407.

Dawson, D. R., Catanzaro, A. M., Firestone, J., Schwartz, M., \& Stuss, D. T. (2006). Changes in coping style following traumatic brain injury and their relationship to productivity status. Brain and Cognition, 60, 214-216.

De Bie, S. E. (1987). Standaardvragen 1987: Voorstellen voor uni-formering van vraagstellingen naar achtergrondkenmerken en interviews [Standard questions 1987: Proposal for uniformization of questions regarding background variables and interviews]. Leiden, The Netherlands: Leiden University Press.

Dikmen, S. S. (1995). One year psychosocial outcome in head injury. Journal of the International Neuropsychological Society, 1, 67-77.

Engberg, A. W., \& Teasdale, T. W. (2004). Psychosocial outcome following traumatic brain injury in adults: A long-term population-based follow-up. Brain Injury, 18, 533-545.

Finset, A., \& Andersson, S. (2000). Coping strategies in patients with acquired brain injury: Relationships between coping, apathy, depression and lesion location. Brain Injury, 14, 887-905.

Folkman, S., Lazarus, R. S., Gruen, R. J., \& DeLongis, A. (1986). Appraisal, coping, health status, and psychological symptoms. Journal of Personality and Social Psychology, 50, 571-579.

Fugl-Meyer, A. R., Branholm, I. B., \& Fugl-Meyer, K. S. (1991). Happiness and domain specific life satisfaction in adult northern Swedes. Clinical Rehabilitation, 5, 25-33.

Goldstein, K. (1952). The effect of brain damage on the personality. Psychiatry, 15, 245-260.

Hepp, U., Moergeli, H., Buchi, S., Wittmann, L., \& Schnyder, U. (2005). Coping with serious accidental injury: A one-year follow-up study. Psychotherapy and Psychosomatics, 74, 379-386.

Herrmann, M., Curio, N., Petz, T., Synowitz, H., Wagner, S., Bartels, C., et al. (2000). Coping with illness after brain diseases: a comparison between patients with malignant brain tumors, stroke, Parkinson's disease and traumatic brain injury. Disability and Rehabilitation, 22, 539-546. 
Hoofien, D., Gilboa, A., Vakil, E., \& Donovick, P. J. (2001). Traumatic brain injury (TBI) 10-20 years later: A comprehensive outcome study of psychiatric symptomatology, cognitive abilities and psychosocial functioning. Brain Injury, 15, 189-209.

Kendall, E., \& Terry, D. J. (1996). Psychosocial adjustment following closed head injury: A model for understanding individual differences and predicting outcome. Neuropsychological Rehabilitation, 6, 101-132.

Krpan, K. M., Levine, B., Stuss, D. T., \& Dawson, D. R. (2007). Executive function and coping at one-year post traumatic brain injury. Journal of Clinical and Experimental Neuropsychology, 29, 36-46.

Lazarus, R. S. (1993). Coping theory and research: Past, present, and future. Psychosomatic Medicine, 55, 234-247.

Lazarus, R. S., \& Folkman, S. (1985). Stress, Appraisal, and Coping (Vol. 2). New York: Springer.

McCarthy, M. L., Dikmen, S. S., Langlois, J. A., Selassie, A. W., Gu, J. K., \& Horner, M. D. (2006). Self-reported psychosocial health among adults with traumatic brain injury. Archives of Physical Medicine and Rehabilitation, 87, 953-961.

Ownsworth, T., \& McFarland, K. (2004). Investigation of psychological and neuropsychological factors associated with clinical outcome following a group rehabilitation programme. Neuropsychological Rehabilitation, 14, 535-562.

Pagulayan, K. F., Temkin, N. R., Machamer, J., \& Dikmen, S. S. (2006). A longitudinal study of health-related quality of life after traumatic brain injury. Archives of Physical Medicine and Rehabilitation, 87, 611-618.

Post, M. W. M., de Witte, L. P., van Asbeck, F. W. A., van Dijk, A. J., \& Schrijvers, A. J. P. (1998). Predictors of health status and life satisfaction in spinal cord injury. Archives of Physical Medicine and Rehabilitation, 79, 395-401.

Prigatano, G. P. (1999). Principles of Neuropsychological Rehabilitation. New York: Oxford University Press.

Schreurs, P. J. G., van de Willege, G., Brosschot, J. F., Tellegen, B., \& Graus, G. M. H. (1993). De Utrechtse coping lijst: UCL: Omgaan met problemen en gebeurtenissen. Utrecht: Swets en Zeitlinger.

Tomberg, T., Toomela, A., Pulver, A., \& Tikk, A. (2005). Coping strategies, social support, life orientation and health-related quality of life following traumatic brain injury. Brain Injury, 19, 1181-1190.

Van Baalen, B., Ribbers, G. M., Medema-Meulepas, D., Pas, M. S., Odding, E., \& Stam, H. J. (2007). Being restricted in participation after a traumatic brain injury is negatively associated by passive coping style of the caregiver. Brain Injury, 21, 925-931.

vanStraten, A., deHaan, R. J., Limburg, M., Schuling, J., Bossuyt, P. M., \& vandenBos, G. A. M. (1997). A stroke-adapted 30-item version of the sickness impact profile to assess quality of life (SA-SIP30). Stroke, 28, 2155-2161.

Visser-Meily, A., Post, M., Schepers, V., \& Lindeman, E. (2005). Spouses' quality of life 1 year after stroke: Prediction at the start of clinical rehabilitation. Cerebrovascular Diseases, 20, 443-448.

Wilson, B. A. (2000). Compensating for cognitive deficits following brain injury. Neuropsychology Review, 10, 233-243.

Wolters, G., Stapert, S., Brands, I., \& van Heugten, C. (in press). Coping following acquired brain injury: Predictors and correlates. Journal of Head Trauma Rehabilitation.

Manuscript received October 2009

Revised manuscript received February 2010

First published online May 2010 